\title{
Correction to: A non-canonical $\Delta 9$-desaturase synthesizing palmitoleic acid identified in the thraustochytrid Aurantiochytrium sp. T66
}

\author{
E-Ming Rau ${ }^{1} \cdot$ Inga Marie Aasen ${ }^{2} \cdot$ Helga Ertesvåg $^{1}$
}

Published online: 18 September 2021

(c) Springer-Verlag GmbH Germany, part of Springer Nature 2021

Correction to: Applied Microbiology and Biotechnology

https://doi.org/10.1007/s00253-021-11425-5

The original version of this article inadvertently contained a mistake since Supplemental Fig. S1 had not been reproduced properly. This is being corrected in this publication.

Supplementary Information The online version contains supplementary material available at https://doi.org/10.1007/s00253-021-11562-x.

Publisher's note Springer Nature remains neutral with regard to jurisdictional claims in published maps and institutional affiliations.

The original article can be found online at https://doi.org/10.1007/ s00253-021-11425-5.

Helga Ertesvåg

helga.ertesvag@ntnu.no

1 Department of Biotechnology and Food Science, NTNU

Norwegian University of Science and Technology,

Trondheim, Norway

2 Department of Biotechnology and Nanomedicine, SINTEF Industry, Trondheim, Norway 